\title{
Why the categorization of indexed effective orifice area is not justified for the classification of prosthesis- patient mismatch
}

\author{
Michiel D. Vriesendorp, MD, ${ }^{\mathrm{a}}$ G. Michael Deeb, MD, ${ }^{\mathrm{b}}$ Michael J. Reardon, MD, ${ }^{\mathrm{c}}$ Bob Kiaii, MD, ${ }^{\mathrm{d}}$ \\ Vinayak Bapat, MD, ${ }^{\mathrm{e}}$ Louis Labrousse, MD ${ }^{\mathrm{f}}{ }^{\mathrm{V}}$ Vivek Rao, MD, ${ }^{\mathrm{g}}$ Joseph F. Sabik III, MD, ${ }^{\mathrm{h}}$ \\ Elizabeth Gearhart, MS, ${ }^{\mathrm{i}}$ and Robert J. M. Klautz, MD, PhD ${ }^{\mathrm{a}}$
}

\begin{abstract}
Objectives: Although the impact of prosthesis-patient mismatch (PPM) on survival has been widely studied, there has been little debate about whether the current definition of PPM truly reflects hemodynamic obstruction. This study aimed to validate the categorization of indexed effective orifice area (EOAi) for the classification of PPM.

Methods: In total, 2171 patients who underwent aortic valve replacement with a surgical stented bioprosthesis in 5 trials (CoreValve US High-Risk, SURTAVI [Surgical Replacement and Transcatheter Aortic Valve Implantation Trial], Evolut Low Risk, PERIGON [PERIcardial SurGical AOrtic Valve ReplacemeNt] Pivotal Trial for the Avalus valve, and PERIGON Japan) were used for this analysis. The echocardiographic images at the 1-year follow-up visit were evaluated to explore the association between EOAi and mean aortic gradient and its interaction with other patient characteristics, including obesity. In addition, different criteria of PPM were compared with reflect elevated mean aortic gradients $(\geq 20 \mathrm{~mm} \mathrm{Hg})$.
\end{abstract}

Results: A relatively smaller exponential decay in mean aortic gradient was found for increasing EOAi, as the slope on the log scale was -0.83 versus -2.5 in the publication from which the current cut-offs for PPM originate. The accuracy of the American Society of Echocardiography, Valve Academic Research Consortium-2, and European Association of Cardiovascular Imaging definitions of PPM to reflect elevated mean aortic gradients was $49 \%, 57 \%$, and $57 \%$, respectively. The relation between EOAi and mean aortic gradient was not significantly different between obese and non-obese patients $(P=.20)$.

Conclusions: The use of EOAi thresholds to classify patients with PPM is undermined by a less-pronounced exponential relationship between EOAi and mean aortic gradient than previously demonstrated. Moreover, recent adjustment for obesity in the definition of PPM is not supported by these data. (J Thorac Cardiovasc Surg 2022;164:822-9)

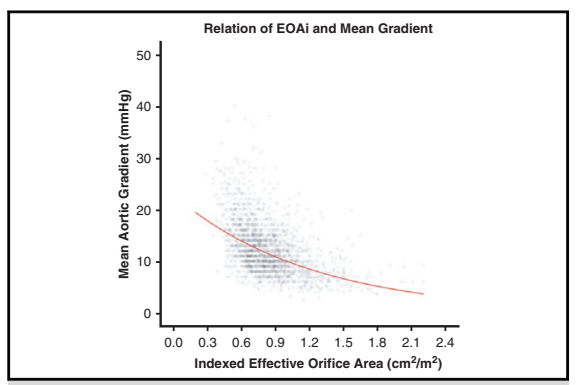

The near-linear relation between EOAi and mean gradient hampers the definition of cut-off values.

\section{CENTRAL MESSAGE}

The categorization of indexed effective orifice area for the classification of PPM is not justified.

\section{PERSPECTIVE}

Our validation study showed that the categorization of indexed effective orifice area (EOAi) to classify patients with prosthesis-patient mismatch (PPM) is undermined by a lesspronounced exponential relationship between EOAi and mean aortic gradient than previously demonstrated by Pibarot and Dumesnil. Moreover, recent adjustment for obesity in the definition of PPM is not supported.

See Commentaries on pages $830,831,833$.
From the ${ }^{a}$ Department of Cardiothoracic Surgery, Leiden University Medical Center, Leiden, The Netherlands; ${ }^{b}$ Department of Cardiac Surgery, University of Michigan Health System-University Hospital, Ann Arbor, Mich; ${ }^{\mathrm{c} D e p a r t m e n t}$ of Cardiothoracic Surgery, Houston Methodist DeBakey Heart and Vascular Center, Houston, Tex; ${ }^{\mathrm{d} D e p a r t m e n t}$ of Cardiovascular and Thoracic Surgery, London Health Sciences Centre, London, Ontario, Canada; ${ }^{\text {e}}$ Department of Surgery, Columbia University Irving Medical Center/New York-Presbyterian Hospital, New York, NY; ${ }^{\mathrm{f}}$ Medico-Surgical Department of Valvulopathies, CHU Hospital of Bordeaux, Bordeaux, France; ${ }^{g}$ Department of Cardiovascular Surgery, Toronto General Hospital, Toronto, Ontario, Canada; ${ }^{\mathrm{h}}$ Department of Surgery, University Hospitals, Case Western Reserve University School of Medicine, Cleveland, Ohio; and ${ }^{\mathrm{i}} \mathrm{De}-$ partment of Biostatistics, Medtronic, Minneapolis, Minn.

This study was funded by Medtronic.

Current address of Dr Kiaii: Department of Surgery, UC Davis Medical Center, Sacramento, Calif.

ClinicalTrials.gov Identifier: PERIGON Pivotal Trial (NCT02088554), PERIGON Japan Trial (NCT02686814), CoreValve US Pivotal High-Risk Trial
(NCT01240902), SURTAVI Trial (NCT01586910), and Evolut Low-Risk Trial (NCT02701283).

Accepted for the 100th Annual Meeting of The American Association for Thoracic Surgery.

Received for publication June 7, 2020; revisions received Oct 8, 2020; accepted for publication Oct 20, 2020; available ahead of print Nov 12, 2020.

Address for reprints: Michiel D. Vriesendorp, MD, Department of Cardiothoracic Surgery, Leiden University Medical Centre, Albinusdreef 2, Leiden, ZuidHolland 2333 ZA, The Netherlands (E-mail: M.D.Vriesendorp@lumc.nl); or Robert J. M. Klautz, MD, PhD, Department of Cardiothoracic Surgery, Leiden University Medical Centre, Albinusdreef 2, Leiden 2333 ZA, The Netherlands (E-mail: R.J.M.Klautz@lumc.nl). $0022-5223$

Copyright (C 2020 The Author(s). Published by Elsevier Inc. on behalf of The American Association for Thoracic Surgery. This is an open access article under the CC BY license (http://creativecommons.org/licenses/by/4.0/).

https://doi.org/10.1016/j.jtcvs.2020.10.123 


\section{Abbreviations and Acronyms \\ ASE $\quad=$ American Society of \\ Echocardiography \\ AVR = aortic valve replacement \\ BMI = body mass index \\ BSA = body surface area \\ EACVI = European Association of \\ Cardiovascular Imaging \\ EOAi $=$ indexed effective orifice area \\ PERIGON $=$ PERIcardial SurGical AOrtic Valve \\ ReplacemeNt Pivotal Trial for the \\ Avalus valve \\ PPM = prosthesis-patient mismatch \\ SURTAVI $=$ Surgical Replacement and \\ Transcatheter Aortic Valve \\ Implantation Trial \\ TTE $=$ trans-thoracic echocardiography \\ VARC-2 = Valve Academic Research \\ Consortium-2}

pulmonary homografts). ${ }^{9}$ To validate whether EOAi cutoff points to define PPM are justified, this study evaluated the relationship between EOAi and mean aortic gradient in a large, homogeneous cohort of patients receiving stented bioprosthetic valves.

\section{METHODS}

\section{Study Design}

For this analysis, the patients receiving surgical AVR in 5 trials (CoreValve US Pivotal High-Risk, Surgical Replacement and Transcatheter Aortic Valve Implantation [SURTAVI], Evolut Low Risk, PERIcardial SurGical AOrtic Valve ReplacemeNt [PERIGON] Pivotal Trial for the Avalus valve, and PERIGON Japan) were combined. ${ }^{10-14}$ Details of these trials are summarized in Table E1. The informed consent form for each study and country states that the collected data may be used for research beyond the scope of research described in the protocol. In addition, the institutional review board or ethics committee of each participating site approved the informed consent form to be used at its location. For these reasons, additional institutional review board approval was not deemed necessary for this post-hoc study.

In short, the 5 trials included patients who underwent surgical AVR between 2010 and 2018. To exclude the possibility that prosthesis type might confound our results, the current analysis was limited to patients who received a conventional stented bioprosthesis (excluding sutureless valves). The transthoracic echocardiography (TTE) images from the PERIGON trials were reviewed by the Cardiovascular Core Laboratories at MedStar Health Research Institute (Hyattsville, Md), whereas the TTE images of the CoreValve High-Risk, SURTAVI, and Evolut Low Risk trials were reviewed at the Mayo Clinic (Rochester, Minn).

\section{Definition of PPM}

For this study, the TTE images at 1 year were analyzed. EOA was calculated with the continuity equation ${ }^{15}$ : EOA $=$ cross-sectional area LVOT * (velocity-time integral LVOT/velocity-time integral aorta), where LVOT indicates the left ventricular outflow tract. EOAi was determined as EOA divided by body surface area (BSA), which was calculated with the Dubois formula. ${ }^{16}$ According to the original PPM criteria, which are recommended by the American Society of Echocardiography (ASE), PPM is defined by an EOAi $\leq 0.85 \mathrm{~cm}^{2} / \mathrm{m}^{2}$, and more specifically, $0.85 \geq \mathrm{EOAi}>0.65 \mathrm{~cm}^{2} / \mathrm{m}^{2}$ indicates moderate PPM, and an EOAi $\leq 0.65 \mathrm{~cm}^{2} / \mathrm{m}^{2}$ indicates severe PPM. ${ }^{9}, 17$ Recent guidelines have proposed adjustment of these thresholds for patients with obesity, defined as a body mass index (BMI) $\geq 30 \mathrm{~kg} / \mathrm{m}^{2}$. The guidelines of the Valve Academic Research Consortium-2 (VARC-2) define PPM for patients with obesity by an EOAi $\leq 0.70 \mathrm{~cm}^{2} / \mathrm{m}^{2}$, moderate PPM by $0.70 \geq$ EOAi $\geq 0.60 \mathrm{~cm}^{2} / \mathrm{m}^{2}$, and severe PPM by an EOAi $<0.60 \mathrm{~cm}^{2} / \mathrm{m}^{2}$, while using the same cut-offs as the ASE for patients without obesity. ${ }^{18}$ The guidelines of the European Association of Cardiovascular Imaging (EACVI) also use the same cut-offs as the ASE for patients without obesity. ${ }^{19}$ For patients with obesity, they define PPM by an EOAi $\leq 0.70 \mathrm{~cm}^{2} / \mathrm{m}^{2}$, with moderate PPM defined by $0.70 \geq \mathrm{EOAi}>0.55 \mathrm{~cm}^{2} /$ $\mathrm{m}^{2}$ and severe PPM defined by an EOAi $\leq 0.55 \mathrm{~cm}^{2} / \mathrm{m}^{2}$. In accordance with the guidelines of the EACVI and VARC-2, the presence of an elevated mean aortic gradient was defined as a mean aortic gradient $\geq 20 \mathrm{~mm} \mathrm{Hg}$.

\section{Statistical Analyses}

The baseline and procedural characteristics for the combined cohort are reported. Categorical patient characteristics are summarized as frequencies and percentages, and continuous patient characteristics are summarized as means and standard deviations. The association between EOAi and mean aortic gradient at 1 year was explored using an exponential model consistent with the methodology applied by Pibarot and Dumesnil in their seminal publication, on which the original cut-offs are based. ${ }^{9}$ In this paper, the relation between EOAi and mean aortic gradient at rest was expressed as 

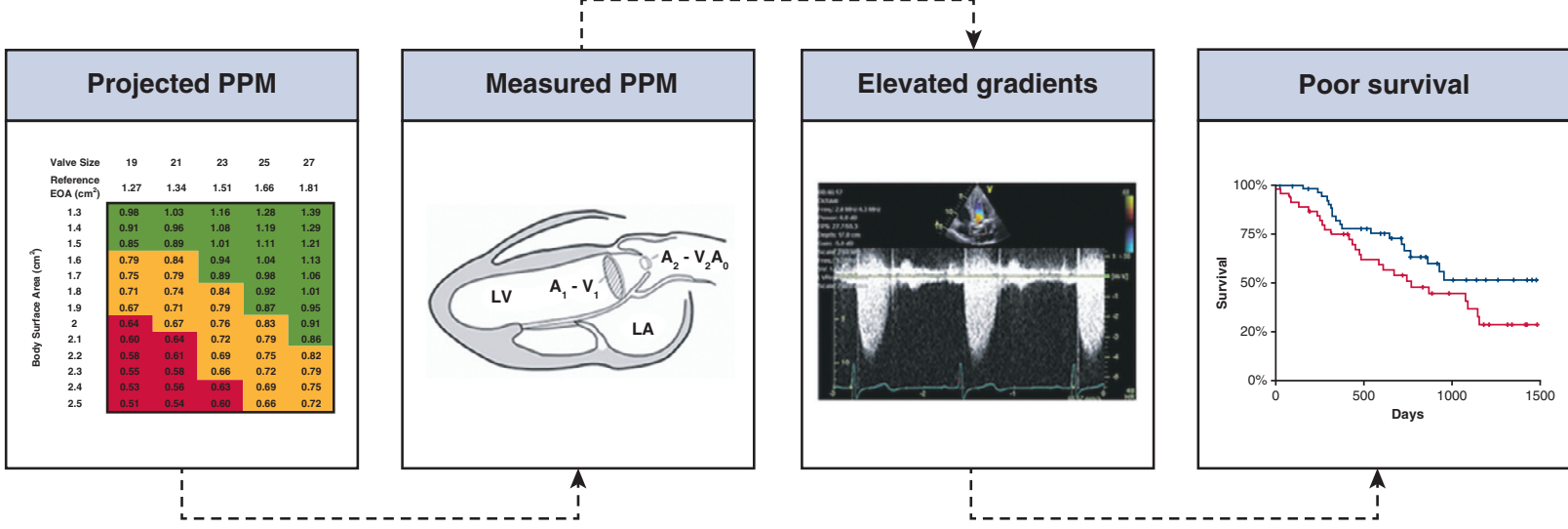

FIGURE 1. Cascade of assumptions to support the use of EOAi charts based on retrospective observational data. When EOAi charts are used to guide prosthetic valve selection, it is (incorrectly) expected that projected PPM corresponds with measured PPM after the procedure. Measured PPM in turn is assumed to reflect a pathologic degree of hemodynamic obstruction, based on the association between PPM and elevated gradients. PPM, Prosthesis-patient mismatch; EOA, effective orifice area. First image is reproduced with permission of Medtronic (Minneapolis, Minn). Second image is from ECHOpedia.org ${ }^{4}$ and is used under a Creative Commons License. Third image is reproduced from Ramaraj and Sorrell, ${ }^{5}$ with permission from BMJ Publishing Group Ltd.

mean aortic gradient $=81.07 * \exp (-\mathrm{EOAi} / 0.40)$. An exponential model of the same functional form was fitted $[\log ($ mean aortic gradient $)=\mathrm{a}+$ $\left.\mathrm{b}^{*} \mathrm{EOAi}+\varepsilon\right]$. Interestingly, the same authors have reported a wide variety of functional forms to express the relation between EOAi and mean aortic gradient. ${ }^{3,9,20}$ To highlight the implications of using these different models, several reported functional forms were fitted to our data.

To analyze the different definitions of PPM, diagnostic measures to reflect elevated mean aortic gradients ( $\geq 20 \mathrm{~mm} \mathrm{Hg}$ ), including sensitivity, specificity, positive predictive value, negative predictive value, and accuracy, were determined. To study the impact of other patient characteristics on the relation between EOAi and mean aortic gradient, a similar exponential model incorporating an interaction term was fit to examine the impact of obesity (BMI $\geq 30 \mathrm{~kg} / \mathrm{m}^{2}$ ), older age ( $\geq 70$ years), poor LV function $(\leq 45 \%)$, and sex on the relation between EOAi and mean aortic gradient. Each variable was added separately to the model. All tests were 2-tailed. The statistical analyses were generated using SAS, version 9.4 (SAS Institute Inc, Cary, NC) and R 3.6.1 (R Development Core Team, Vienna, Austria, 2020).

\section{RESULTS}

\section{Study Cohort}

The baseline and procedural characteristics of the 2171 patients included in this study are presented in Table 1 . The average age at the time of the procedure was $74 \pm 9$ years, $1459(67 \%)$ patients were male, and 525 $(24 \%)$ patients underwent concomitant coronary artery bypass grafting. An overview of the implanted stented bioprosthetic valve types and sizes is presented in Table E2: the most common valve types were the Medtronic Avalus $(47 \%)$ and Edwards PERIMOUNT (25\%). Echocardiographic measurements at baseline and 1 year are summarized in Table 2. At 1 year, mean aortic gradient was $12 \pm 5 \mathrm{~mm} \mathrm{Hg}$ and EOAi was $0.8 \pm 0.3 \mathrm{~cm}^{2} / \mathrm{m}^{2}$. When an exponential model was fit, the observed relation was mean aortic gradient $=22.95 * \exp (-0.83 *$ EOAi $)$. The exponential term of -0.83 implies that a substantially smaller exponential decay in mean aortic gradient for increasing EOAi was found in comparison to Pibarot and Dumesnil (mean aortic gradient $=81.07 * \exp$ $\left[-2.5^{*}\right.$ EOAi] $) .^{9}$ A visual comparison of these 2 curves is provided in Figure 2. ${ }^{3,9,20,21}$ In addition, while different functional forms have been used interchangeably in the literature, ${ }^{3,9,20}$ Figure 3 demonstrates how these models result in different relations between EOAi and mean aortic gradient.

\section{PPM Criteria}

According to the ASE, VARC-2, and EACVI criteria, the incidence of PPM in this study was $58 \%, 49 \%$, and $49 \%$, respectively, at 1 -year follow-up. Furthermore, the incidence of severe PPM was $22 \%, 18 \%$, and $15 \%$, respectively. Figure 4 shows the percentage of patients with elevated mean aortic gradients $(\geq 20 \mathrm{~mm} \mathrm{Hg})$ among patients with no, moderate, or severe PPM according to the ASE, VARC-2, and EACVI guidelines. PPM according to the VARC-2 or EACVI criteria had a positive predictive probability of $14 \%$ to reflect elevated mean aortic gradients, while PPM according to the ASE criteria had a positive predictive probability of $13 \%$. The accuracy of the ASE, VARC-2, and EACVI definitions of PPM to reflect elevated mean aortic gradients was $49 \%, 57 \%$, and $57 \%$, respectively (Table E3).

\section{Interaction With Obesity}

Obesity was prevalent in $882(41 \%)$ patients. The mean aortic gradient in patients with obesity was $13 \pm 6 \mathrm{~mm} \mathrm{Hg}$, and the average EOAi was $0.8 \pm 0.3 \mathrm{~cm}^{2} / \mathrm{m}^{2}$. In comparison, in patients without obesity, the mean aortic gradient was $12 \pm 5 \mathrm{~mm} \mathrm{Hg}$ and the average EOAi was $0.9 \pm 0.3 \mathrm{~cm}^{2} / \mathrm{m}^{2}$. The relation between EOAi and mean aortic gradient was not significantly different $(P=.20)$ 
TABLE 1. Baseline and procedural characteristics of the included patients

\begin{tabular}{|c|c|}
\hline & $\begin{array}{c}\text { Patients } \\
(\mathbf{N}=\mathbf{2 1 7 1})\end{array}$ \\
\hline \multicolumn{2}{|l|}{ Baseline } \\
\hline Age, y & $74 \pm 9(2171)$ \\
\hline Male & $1459 / 2171(67 \%)$ \\
\hline Body surface area, $\mathrm{m}^{2}$ & $2.0 \pm 0.2(2171)$ \\
\hline Body mass index, $\mathrm{kg} / \mathrm{m}^{2}$ & $30 \pm 6(2171)$ \\
\hline \multicolumn{2}{|l|}{ STS risk of mortality, $\%$} \\
\hline Mean \pm SD & $3.1 \pm 2.4(2171)$ \\
\hline Median (quartile 1, quartile 3) & $2.4(1.4,4.3)$ \\
\hline Coronary artery disease & $992 / 1818(55 \%)$ \\
\hline Chronic obstructive pulmonary disease & $446 / 2150(21 \%)$ \\
\hline Diabetes & $688 / 2171(32 \%)$ \\
\hline Myocardial infarction & $250 / 2171(12 \%)$ \\
\hline Peripheral vascular disease & $368 / 2169(17 \%)$ \\
\hline Stroke/CVA & $121 / 1863(7 \%)$ \\
\hline Atrial fibrillation & $381 / 2170(18 \%)$ \\
\hline \multicolumn{2}{|l|}{ Procedure } \\
\hline Median sternotomy & $1774 / 2169(82 \%)$ \\
\hline Concomitant $\mathrm{CABG}$ & $525 / 2169(24 \%)$ \\
\hline \multicolumn{2}{|l|}{ Cardiopulmonary bypass time, $\min$} \\
\hline Mean \pm SD & $101 \pm 39(2154)$ \\
\hline Median (quartile 1, quartile 3) & $93(74,119)$ \\
\hline \multicolumn{2}{|l|}{ Aortic crossclamp time, min } \\
\hline Mean \pm SD & $76 \pm 29(2142)$ \\
\hline Median (quartile 1, quartile 3) & $70(55,91)$ \\
\hline
\end{tabular}

Categorical variables are reported as frequency and percentage. Continuous variables are reported as mean $\pm \mathrm{SD}$ if the distribution was normal and as median (quartile 1, quartile 3) if the distribution was skewed. STS, Society of Thoracic Surgeons; $S D$, standard deviation; $C V A$, cerebrovascular accident; $C A B G$, coronary artery bypass grafting.

between patients with and without obesity (Figure 5). Of the other patient characteristics evaluated in this study, only low-flow status had a significant interaction $(P<.001)$ on the relation of EOAi and mean aortic gradient (Figure E1 and Table E4).

\section{DISCUSSION}

In a large cohort of patients receiving stented bioprostheses, we validated the use of EOAi cut-off values to classify patients with PPM. Our results show that a decrease in EOAi is associated with an increase in gradient; however, the exponential relationship between EOAi and mean aortic gradient was less pronounced in the present analysis (Figure 2) than previously demonstrated. ${ }^{9}$ This finding undermines the categorization of EOAi for the classification of PPM, as the selection of any cut-off value becomes an arbitrary process (Figure 6). Furthermore, the relation between EOAi and mean aortic gradient was not different between patients with and without obesity, suggesting that the use of lower EOAi cut-off values to classify patients with obesity should be reconsidered.

The categorization of the continuous-parameter EOAi may be seen as an extreme form of rounding, with an
TABLE 2. Hemodynamic performance at baseline and 1 year

\begin{tabular}{|c|c|c|}
\hline Assessment & $\begin{array}{c}\text { Baseline } \\
(\mathbf{N}=\mathbf{2 1 4 9})\end{array}$ & $\frac{1 \text { Year }}{(\mathbf{N}=2171)}$ \\
\hline Mean aortic gradient, $\mathrm{mm} \mathrm{Hg}$ & $45 \pm 15(2131)$ & $12 \pm 5(2135)$ \\
\hline Peak aortic gradient, $\mathrm{mm} \mathrm{Hg}$ & $71 \pm 24(1561)$ & $23 \pm 9(1575)$ \\
\hline $\mathrm{EOA}, \mathrm{cm}^{2}$ & $0.8 \pm 0.4(1958)$ & $1.6 \pm 0.5(1983)$ \\
\hline EOAi, $\mathrm{cm}^{2} / \mathrm{m}^{2}$ & $0.4 \pm 0.2(1958)$ & $0.8 \pm 0.3(1982)$ \\
\hline Doppler velocity index & $0.2 \pm 0.1(2057)$ & $0.5 \pm 0.1(2077)$ \\
\hline $\begin{array}{l}\text { Left ventricular ejection } \\
\text { fraction, } \%\end{array}$ & $60 \pm 10(1953)$ & $62 \pm 9(1966)$ \\
\hline Stroke volume, $\mathrm{mL}$ & $80 \pm 21(1965)$ & $78 \pm 21(1996)$ \\
\hline $\begin{array}{l}\text { Indexed stroke volume, } \\
\mathrm{mL} / \mathrm{m}^{2}\end{array}$ & $41 \pm 11(1965)$ & $40 \pm 10(1982)$ \\
\hline \multicolumn{3}{|l|}{$\begin{array}{l}\text { Prosthesis-patient } \\
\text { mismatch (ASE) }\end{array}$} \\
\hline No PPM & NA & $826 / 1982(42 \%)$ \\
\hline Moderate PPM & NA & $715 / 1982(36 \%)$ \\
\hline Severe PPM & NA & $441 / 1982(22 \%)$ \\
\hline \multicolumn{3}{|l|}{$\begin{array}{l}\text { Prosthesis-patient } \\
\text { mismatch (VARC-2) }\end{array}$} \\
\hline No PPM & NA & $1016 / 1982(51 \%)$ \\
\hline Moderate PPM & NA & $610 / 1982(31 \%)$ \\
\hline Severe PPM & NA & $356 / 1982(18 \%)$ \\
\hline \multicolumn{3}{|l|}{$\begin{array}{l}\text { Prosthesis-patient } \\
\text { mismatch (EACVI) }\end{array}$} \\
\hline No PPM & NA & $1016 / 1982(51 \%)$ \\
\hline Moderate PPM & NA & $664 / 1982(34 \%)$ \\
\hline Severe PPM & NA & $302 / 1982(15 \%)$ \\
\hline
\end{tabular}

Categorical variables are reported as frequency and percentage, and continuous variables, as mean \pm standard deviation. EOA, Effective orifice area; EOAi, indexed effective orifice area; ASE, American Society of Echocardiography; $P P M$, prosthesis-patient mismatch; NA, not available; VARC-2, Valve Academic Research Consortium-2; EACVI, European Association of Cardiovascular Imaging.

inevitable loss of information and power. ${ }^{8}$ Its use for the definition of PPM has seemingly been justified by previous evidence of a strong curvilinear relation between EOAi and mean aortic gradient at rest. ${ }^{22}$ The presence of a correlation between these measurements is not surprising, considering that both EOAi and mean aortic gradient are based on the same measurement of the velocity curve across the prosthesis with continuous-wave Doppler. By definition, mathematical coupling will occur between EOAi and mean aortic gradient, as these are not independent measures. As noted previously by Blackstone and colleagues, ${ }^{23}$ it may be "stretching the statistics" to conclude that EOAi is the best parameter of relative valve size based on the obligatory correlation between EOAi and mean aortic gradient.

Furthermore, the selection of a specific EOAi threshold for the classification of PPM has been based by Pibarot and Dumesnil on the point where the increase in mean aortic gradient accelerates. This becomes problematic as a variety 


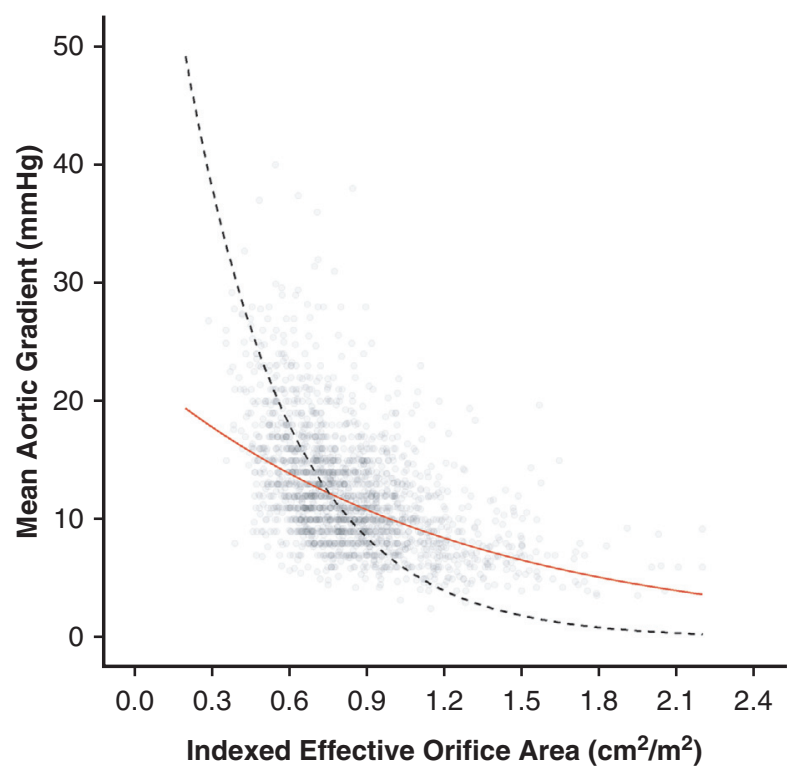

FIGURE 2. Relation between EOAi and mean aortic gradient. In the current analysis $(\mathrm{n}=2171)$, a smaller exponential decay of mean gradient was found (red line) than the reported curve (black line) by Pibarot and Dumesnil, ${ }^{9}$ on which the current cut-off value of $0.85 \mathrm{~cm}^{2} / \mathrm{m}^{2}$ to classify patients with prosthesis-patient mismatch is based.

of different functional forms have been used to express the relation of EOAi and mean aortic gradient in their publications about PPM. ${ }^{3,9,20}$ While no argumentation has been provided, the use of one functional form over another has major implications on the observed relation between EOAi and mean aortic gradient, and thus the point of maximal acceleration, as demonstrated in Figure 3. While the selection of the optimal method to model this relation is a study topic on its own, we chose to validate the functional form used in Figure 3, A, in the $J A C C$ article from 2000 as the current cut point of $0.85 \mathrm{~cm}^{2} / \mathrm{m}^{2}$ for the classification of PPM originates from this publication. ${ }^{9}$

Aside from these methodologic concerns, the exponential relationship between EOAi and mean aortic gradient was less pronounced in the present analysis (Figure 2) than previously demonstrated. ${ }^{9}$ As a result, the currently used cut-off values to define PPM poorly distinguished between patients with and without elevated gradients. This limited discriminative ability of PPM may explain why its negative impact on survival is not always evident in the literature. ${ }^{24,25}$ The discrepancy between the results of the Quebec group and our study may be attributed to the types of prosthetic valves used in each study. For instance, we choose to only include stented bioprosthetic valves as they are the most commonly used valves, whereas their study included a combination of homografts, autografts, and stentless valves with only $13 \%$ stented bioprosthetic valves. Although there remains variation in hemodynamic

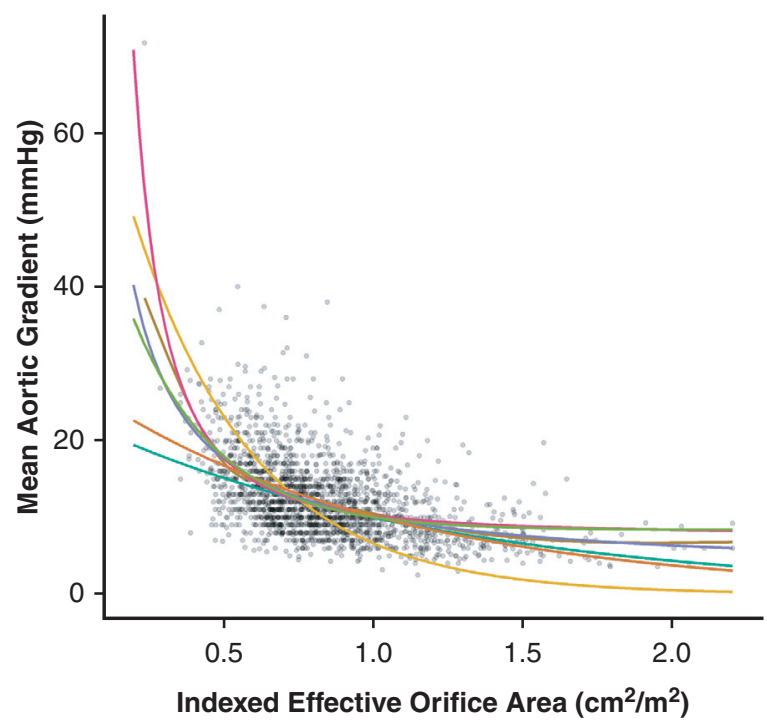

$\begin{array}{ll}\text { Model } & \\ \text { - } \log (\mathrm{Y})=\mathrm{a}+\mathrm{bX} & \mathrm{Y}=\mathrm{a} \cdot \exp (-\mathrm{X} / \mathrm{b})^{\star} \\ -\mathrm{Y}=\mathrm{a}+\mathrm{b} / \mathrm{X} & -\mathrm{Y}=\mathrm{a}+\mathrm{b} / \mathrm{X}^{2} \\ -\mathrm{Y}=\mathrm{c}+(\mathrm{a}-\mathrm{c}) \cdot \exp (-\mathrm{X} / \mathrm{b}) & - \text { Pibarot and Dumesnil } \\ \text { Spline } & \end{array}$

FIGURE 3. Models of mean aortic gradient as a function of EOAi. The relation between EOAi and mean aortic gradient was fitted according to 5 different functional forms that have been published to model this relation. ${ }^{3,9,20}$ A spline and the reported curve by Pibarot and Dumesnil ${ }^{9}$ was added as a reference. ${ }^{*}$ The functional form is equivalent to $\log (\mathrm{Y})=\mathrm{a}+$ $\mathrm{bX}$ but was estimated using dose-response curve methodology. ${ }^{21}$

function within the group of stented bioprosthetic valves itself, we believe that the relative homogeneity of our cohort reduces potential variability due to hemodynamic differences in implanted valve types.

Our findings suggest that the categorization of EOAi into different degrees of PPM has little value. In addition, this study also supports the argument that the use of EOAi charts is not justified by the current evidence. Previously, we demonstrated that a patient with projected PPM does not automatically have measured PPM. ${ }^{6}$ This study adds evidence that a patient with measured PPM does not necessarily have elevated gradients. Together, these results undermine the cascade of assumptions that are required to support the use of EOAi charts from observational studies that found PPM to be a predictor of all-cause mortality ${ }^{1,2}$ (Figure 1). While the use of EOAi charts could be beneficial, its clinical value should be determined in a randomized controlled trial first.

An additional finding of this study was that the relation between EOAi and mean aortic gradient did not differ between and patients with and without obesity, suggesting that the use of lower cut-off values of EOAi to classify patients with obesity should be reconsidered. While it is 


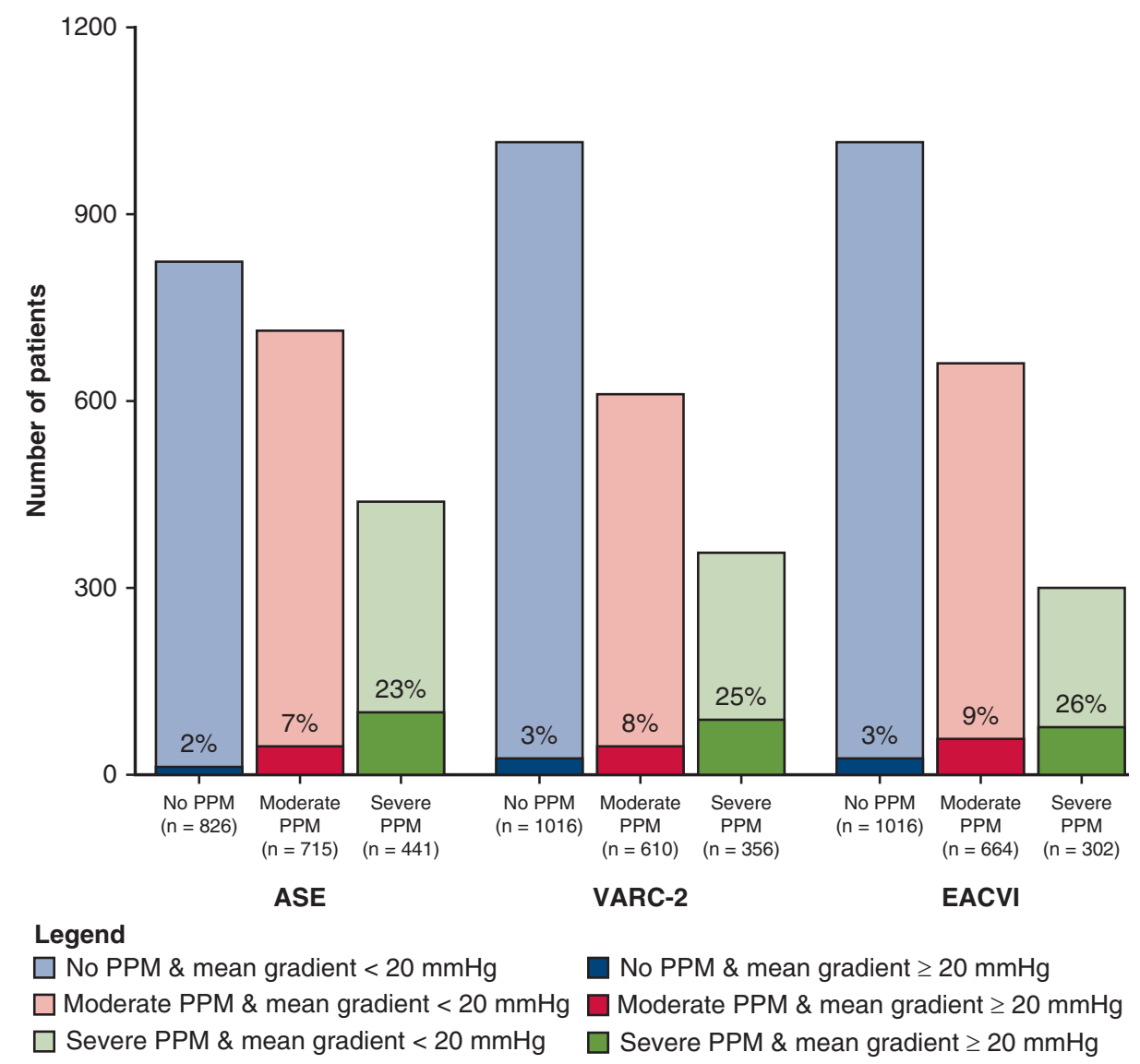

FIGURE 4. Comparison of PPM and elevated mean aortic gradient found with 3 sets of criteria to define PPM. Incidence of none (blue), moderate (red), and severe (green) PPM according to the ASE, VARC-2, and EACVI criteria. The light-shaded area within each PPM category represents the number of patients with a normal mean gradient $(<20 \mathrm{~mm} \mathrm{Hg})$. The dark-shaded area reflects the number of patients with an elevated mean gradient $(\geq 20 \mathrm{~mm} \mathrm{Hg})$, which is also given as a percentage of all patients within each PPM category. PPM, Prosthesis-patient mismatch; ASE, American Society of Echocardiography; VARC-2, Valve Academic Research Consortium-2; EACVI, European Association of Cardiovascular Imaging.

plausible that patients with obesity have relatively lower hemodynamic requirements compared to patients without obesity for a similar BSA, separate cut-off values for patients with a $\mathrm{BMI} \geq 30 \mathrm{~kg} / \mathrm{m}^{2}$ are not based on empirical evidence (Figure 5). In light of the poor accuracy of VARC-2 and EACVI criteria to reflect elevated gradients, using BMI-adjusted cut-off values insufficiently improves the precision of PPM to reflect hemodynamic obstruction.

There was a significant interaction on the relation between EOAi and mean aortic gradient of low-flow status (indexed stroke volume $<35 \mathrm{~mL} / \mathrm{m}^{2}$ ) at the time of the TTE. However, this finding must be interpreted with caution. The calculation of EOAi is identical to that of indexed stroke volume, aside from the measurement of the velocity curve across the prosthesis. As mentioned before, this measurement is also used to calculate mean aortic gradient. Due to the overlap of measurements, patients with low EOAi and low gradient will automatically have low-flow status (Figure E1). However, even in the patients with normalflow status, the exponential relationship between EOAi and mean aortic gradient was less pronounced in the present analysis $($ mean aortic gradient $=29.93 * \exp [-1.01 *$ EOAi $])$ than previously demonstrated.

For future studies that focus on the clinical impact of decreasing EOAi, we recommend analysis of EOAi as a continuous variable. This recommendation should be considered with caution, however, as a wide range in gradients were observed for a specific EOAi (Figure 2). This range could indicate either that the valve opening area is not accurately estimated by EOA or that BSA is a poor proxy for the flow requirements of the patient. Further analyses are planned to investigate whether the correction of EOA with BSA is appropriate.

\section{Limitations}

A key limitation of this study is that only echocardiographic measurements were used to analyze the relation between EOAi and mean aortic gradient. While this was consistent with the original study that was validated, there is by definition mathematical coupling as those parameters are not independently measured. ${ }^{23}$ It would be more accurate to use independent measurements of EOAi, mean aortic 


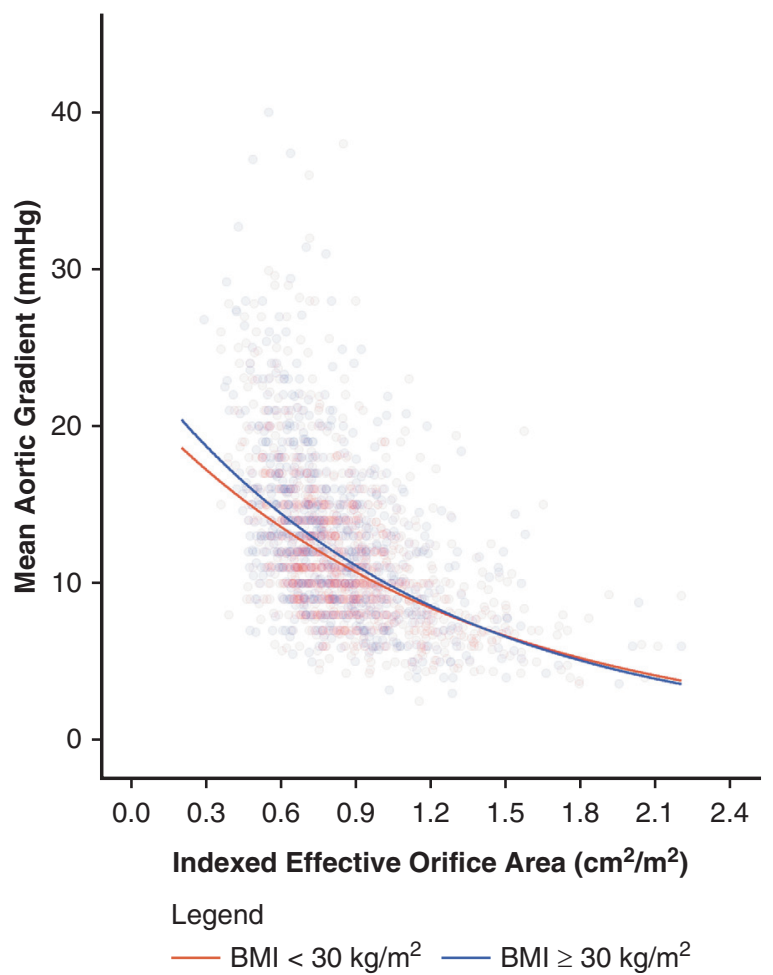

FIGURE 5. Impact of obesity on the relation between indexed effective orifice area (EOAi) and mean aortic gradient at 1 year. The relation between EOAi and mean gradient was not significantly different $(P=.20)$ between patients with and without obesity. $B M I$, Body mass index. gradient, and stroke volume when the relation between these parameters is established. This requires other diagnostic tools, such as cardiac catheterization or magnetic resonance imaging, which were not performed in our study cohort.

\section{CONCLUSIONS}

The categorization of EOAi to classify patients with PPM is undermined by the near-linear relation between EOAi and mean aortic gradient found in our study. Moreover, recent adjustment for obesity in the definition of PPM is not supported by these data. To conclude, current cut-off values of PPM cannot be used to avoid hemodynamic obstruction.

\section{Conflict of Interest Statement}

Dr Vriesendorp receives research support from Medtronic. Dr Deeb serves on an advisory board and as a proctor for Medtronic; as a consultant and research investigator for Edwards Lifesciences; as a consultant and proctor for Terumo; and as a research investigator for Gore Medical (he receives no personal remunerations). Dr Reardon provides educational services to Medtronic, with fees paid to his department. Dr Kiaii has received personal fees from Medtronic and Boston Scientific as a proctor, consultant, and speaker; has received consulting and speaking fees from Johnson \& Johnson; and has received fees from Edwards

The categorization of EOAi is not justified for the classification of PPM
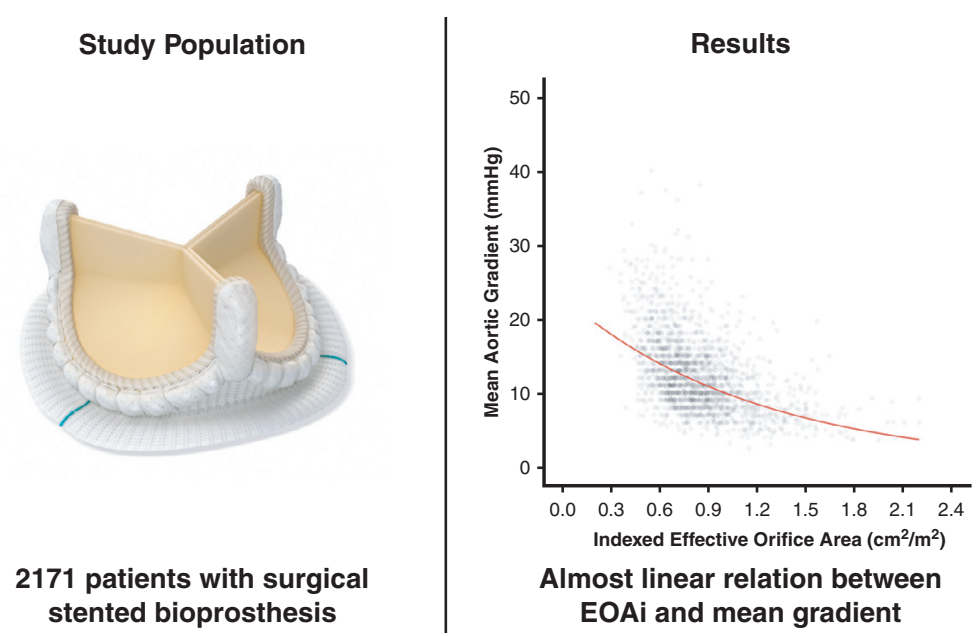

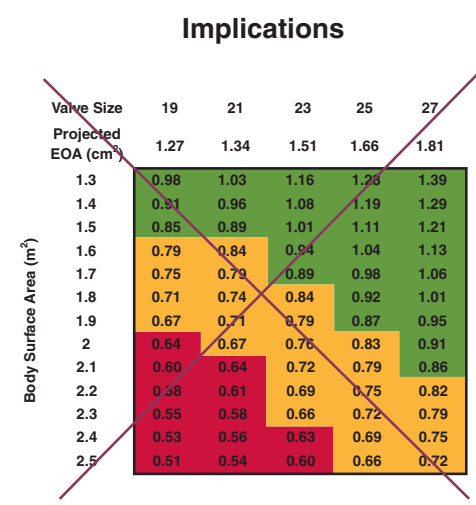

Any EOAi cut-off value to classify PPM is arbitrary

FIGURE 6. The aim of this study is to validate the categorization of indexed effective orifice area (EOAi) for the classification of PPM after aortic valve replacement. As the found relation between EOAi and mean aortic gradient was almost linear in a cohort of patients with stented bioprosthetic valves $(\mathrm{n}=2171)$, the use of EOAi cut-off values to classify patients with PPM is not justified. PPM, Prosthesis-patient mismatch. The left and right images are reproduced with permission of Medtronic (Minneapolis, Minn). 
Lifesciences as a member of the Canadian advisory board, consultant, and proctor. Dr Bapat is a consultant for Medtronic and Boston Scientific and has received speaker fees from Medtronic, Edwards Lifesciences, Boston Scientific, and LivaNova. Dr Rao is a member of the Surgical Advisory Board for Medtronic and a consultant for Abbott Labs. Dr Sabik is a member of the Cardiac Surgery Advisory Board for and the North American Principal Investigator (PI) for the PERIGON Pivotal Trial, and he teaches mitral valve repair techniques for Medtronic. He is the local PI for the Intuity Trial (sponsored by Edwards Lifesciences) and the North American PI for the EXCEL trial (sponsored by Abbott). Ms Gearhart is an employee of Medtronic. Prof Klautz receives research support from Medtronic, consultation and proctoring fees from Medtronic and LivaNova, and participates in speakers' bureaus for Medtronic, LivaNova, and Edwards Lifesciences. Dr Labrousse reported no conflicts of interest.

The Journal policy requires editors and reviewers to disclose conflicts of interest and to decline handling or reviewing manuscripts for which they may have a conflict of interest. The editors and reviewers of this article have no conflicts of interest.

The analyses for this study were proposed and designed by the first and senior authors. The primary data analyses followed the methodology of Pibarot and Dumesnil. ${ }^{9}$ The first and senior authors had full access to all data generated for the manuscript.

\section{References}

1. Head SJ, Mokhles MM, Osnabrugge RL, Pibarot P, Mack MJ, Takkenberg JJ, et al. The impact of prosthesis-patient mismatch on long-term survival after aortic valve replacement: a systematic review and meta-analysis of 34 observational studies comprising 27186 patients with 133141 patient-years. Eur Heart J. 2012;33:1518-29.

2. Sa M, de Carvalho MMB, Sobral Filho DC, Cavalcanti LRP, Rayol SDC, Diniz RGS, et al. Surgical aortic valve replacement and patient-prosthesis mismatch: a meta-analysis of 108182 patients. Eur J Cardiothorac Surg. 2019;56:44-54.

3. Pibarot P, Dumesnil JG. Prosthesis-patient mismatch: definition, clinical impact, and prevention. Heart. 2006;92:1022-9.

4. Aortic Valve Stenosis. ECHOpedia. Available at: https://www.echopedia.org/ wiki/Aortic_Valve_Stenosis. Accessed July 6, 2020.

5. Ramaraj R, Sorrell VL. Degenerative aortic stenosis. BMJ. 2008;336:550-5.

6. Vriesendorp MD, Van Wijngaarden RAFDL, Head SJ, Kappetein A-P, Hickey GL, Rao V, et al. The fallacy of indexed effective orifice area charts to predict prosthesis-patient mismatch after prosthesis implantation. Eur Heart J Cardiovasc Imaging. 2020;21:1116-22.

7. Altman DG, Royston P. The cost of dichotomising continuous variables. BMJ. 2006;332:1080

8. Royston P, Altman DG, Sauerbrei W. Dichotomizing continuous predictors in multiple regression: a bad idea. Stat Med. 2006;25:127-41.

9. Pibarot P, Dumesnil JG. Hemodynamic and clinical impact of prosthesis-patient mismatch in the aortic valve position and its prevention. J Am Coll Cardiol. 2000; 36:1131-41.
10. Klautz RJM, Kappetein AP, Lange R, Dagenais F, Labrousse L, Bapat V, et al Safety, effectiveness and haemodynamic performance of a new stented aortic valve bioprosthesis. Eur J Cardiothorac Surg. 2017;52:425-31.

11. Reardon MJ, Van Mieghem NM, Popma JJ, Kleiman NS, Søndergaard L, Mumtaz M, et al. Surgical or transcatheter aortic-valve replacement in intermediate-risk patients. N Engl J Med. 2017;376:1321-31.

12. Adams DH, Popma JJ, Reardon MJ, Yakubov SJ, Coselli JS, Deeb GM, et al Transcatheter aortic-valve replacement with a self-expanding prosthesis. N Engl J Med. 2014 8;370:1790-8.

13. Popma JJ, Deeb GM, Yakubov SJ, Mumtaz M, Gada H, O’Hair D, et al. Transcatheter aortic-valve replacement with a self-expanding valve in low-risk patients. N Engl J Med. 2019;380:1706-15.

14. Okita Y. PERIGON Japan Clinical Trial. Presented at: 50th Annual Meeting of the Japanese Society for Cardiovascular Surgery; August 17-19, 2020; Fukushima, Japan.

15. Richards KL. Assessment of aortic and pulmonic stenosis by echocardiography Circulation. 1991;84(3 suppl):I182-7.

16. Du Bois D, Du Bois EF. A formula to estimate the approximate surface area if height and weight be known. Arch Intern Med. 1916;XVII:863-71.

17. Zoghbi WA, Chambers JB, Dumesnil JG, Foster E, Gottdiener JS, Grayburn PA, et al. Recommendations for evaluation of prosthetic valves with echocardiography and Doppler ultrasound: a report from the American Society of Echocardiography's guidelines and standards committee and the task force on prosthetic valves, developed in conjunction with the American College of Cardiology Cardiovascular Imaging Committee, Cardiac Imaging Committee of the American Heart Association, the European Association of Echocardiography, a registered branch of the European Society of Cardiology, the Japanese Society of Echocardiography and the Canadian Society of Echocardiography, Endorsed by the American College of Cardiology Foundation, American Heart Association, European Association of Echocardiography, a registered branch of the European Society of Cardiology, the Japanese Society of Echocardiography, and Canadian Society of Echocardiography. J Am Soc Echocardiogr. 2009;22:975-1014.

18. Kappetein AP, Head SJ, Genereux P, Piazza N, van Mieghem NM, Blackstone EH, et al. Updated standardized endpoint definitions for transcatheter aortic valve implantation: the Valve Academic Research Consortium-2 consensus document. Eur Heart J. 2012;33:2403-18.

19. Lancellotti P, Pibarot P, Chambers J, Edvardsen T, Delgado V, Dulgheru R, et al Recommendations for the imaging assessment of prosthetic heart valves: a report from the European Association of Cardiovascular Imaging endorsed by the Chinese Society of Echocardiography, the Inter-American Society of Echocardiography, and the Brazilian Department of Cardiovascular Imaging. Eur Heart J Cardiovasc Imaging. 2016;17:589-90.

20. Clavel MA, Rodés-Cabau J, Dumont É, Bagur R, Bergeron S, De Larochellière R, et al. Validation and characterization of transcatheter aortic valve effective orifice area measured by Doppler echocardiography. JACC Cardiovasc Imaging. 2011;4:1053-62.

21. Ritz C, Baty F, Streibig JC, Gerhard D. Dose-response analysis using R. PLoS One. 2016;10:e0146021.

22. Dumesnil JG, Pibarot P. Prosthesis size and prosthesis-patient size are unrelated to prosthesis-patient mismatch. J Thorac Cardiovasc Surg. 2004;127:1852.

23. Blackstone EH, Gillinov AM, Cosgrove DM. Prosthesis size and prosthesispatient size are unrelated to prosthesis-patient mismatch. J Thorac Cardiovasc Surg. 2004;127:1852-4.

24. Swinkels BM, de Mol BA, Kelder JC, Vermeulen FE, ten Berg JM. Prosthesispatient mismatch after aortic valve replacement: effect on long-term survival. Ann Thorac Surg. 2016;101:1388-94.

25. Jamieson WE, Ye J, Higgins J, Cheung A, Fradet GJ, Skarsgard P, et al. Effect of prosthesis-patient mismatch on long-term survival with aortic valve replacement: assessment to 15 years. Ann Thorac Surg. 2010;89:51-9.

Key Words: prosthesis-patient mismatch, aortic valve replacement, hemodynamic assessment, prosthetic valves 


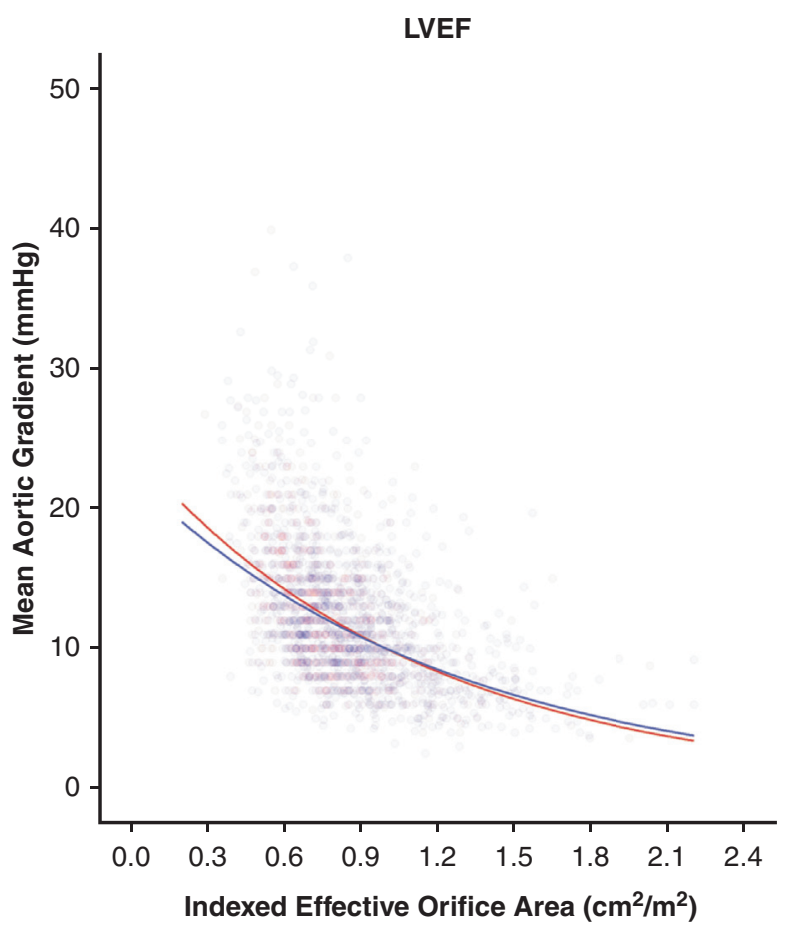

$-<70-\geq 70$

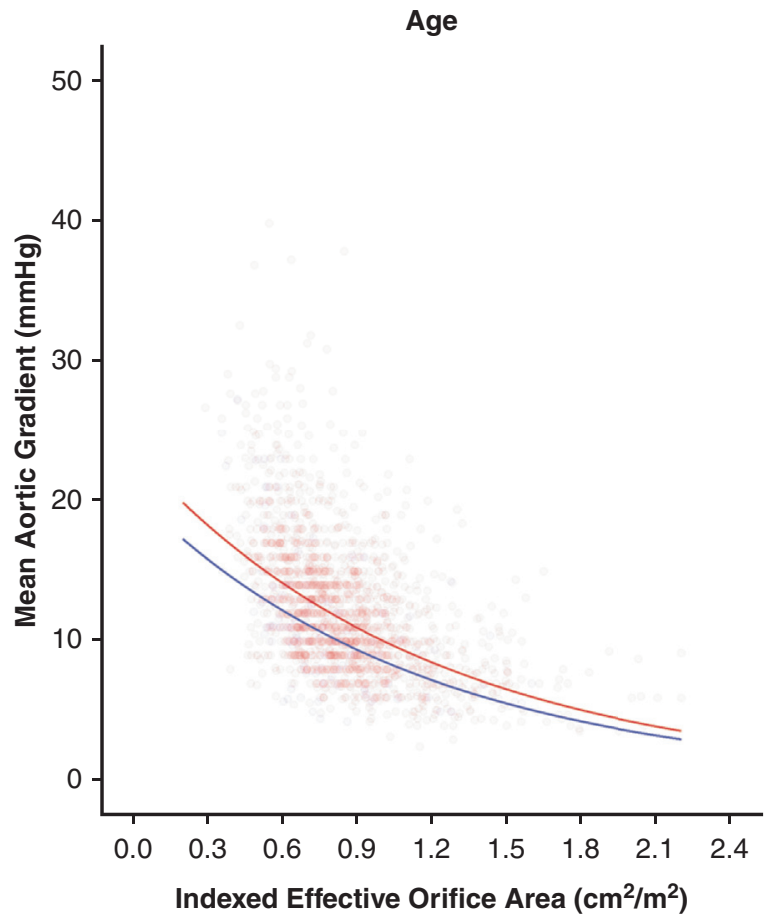

$\longrightarrow 45 \%-\leq 45 \%$

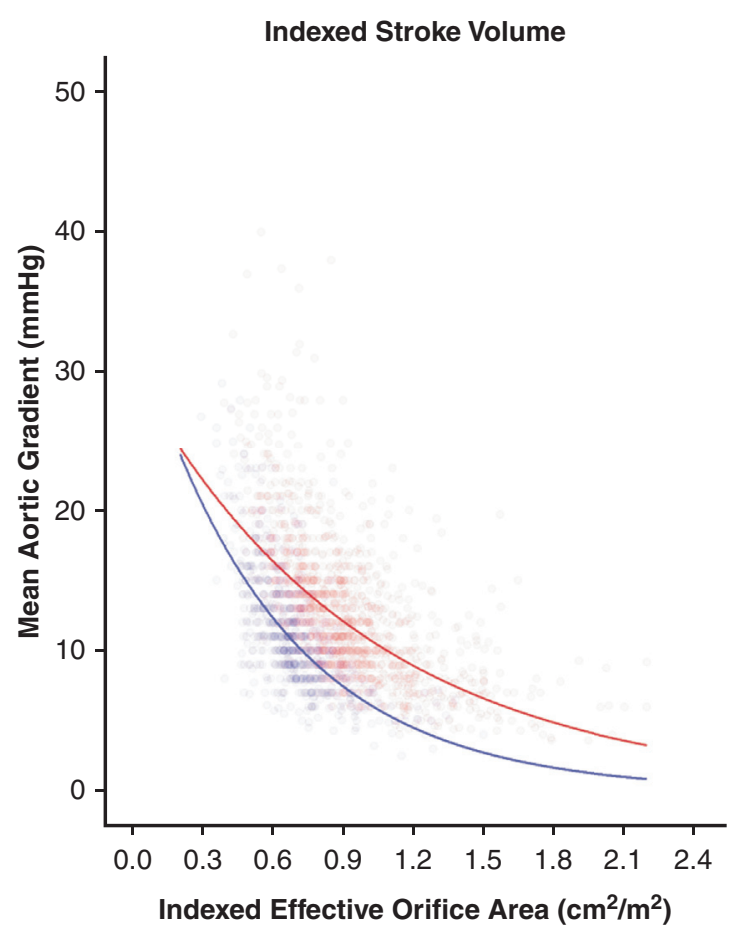

$\longrightarrow 35 \mathrm{~mL} / \mathrm{m}^{2}-<35 \mathrm{~mL} / \mathrm{m}^{2}$

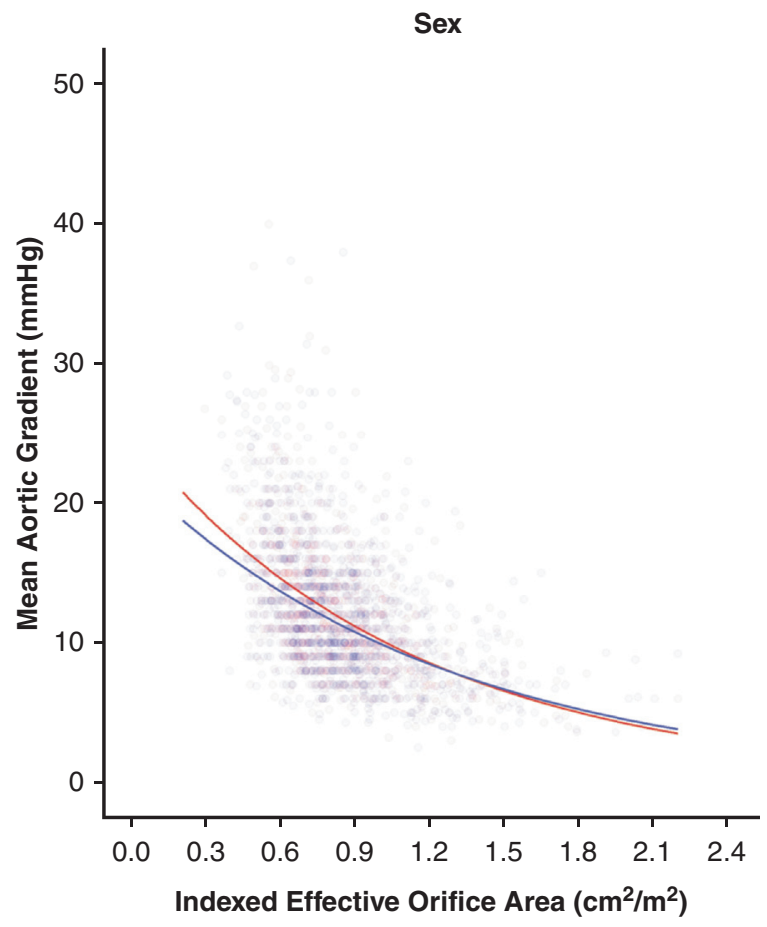

_ Female — Male

FIGURE E1. Interaction of patient characteristics on the relation between indexed effective orifice area and mean aortic gradient. Shown is the relation between indexed effective orifice area and mean aortic gradient, stratified according to LVEF $\geq 45 \%$ vs LVEF $<45 \%$ (left upper panel), indexed stroke volume $\geq 35 \mathrm{~mL} / \mathrm{m}^{2}$ vs $<35 \mathrm{~mL} / \mathrm{m}^{2}$ (right upper panel), age $\geq 70$ years vs $<70$ years (left lower panel), and male vs female (right lower panel). LVEF, Left ventricular ejection fraction. 


\begin{tabular}{|c|c|c|c|c|c|}
\hline & PERIGON Pivotal & PERIGON Japan & CoreValve High Risk & SURTAVI & Evolut Low Risk \\
\hline $\begin{array}{l}\text { No. of patients who received a } \\
\text { surgical bioprosthetic } \\
\text { valve* }\end{array}$ & 1019 & 11 & 214 & 574 & 353 \\
\hline Study type & Prospective, nonrandomized & Prospective, nonrandomized & Randomized & Randomized & Randomized \\
\hline No. of sites & 38 & 8 & 45 & 87 & 86 \\
\hline Geographic location(s) & $\begin{array}{l}\text { Europe, United States, } \\
\text { Canada }\end{array}$ & Japan & United States & $\begin{array}{l}\text { Europe, United States, } \\
\text { Canada }\end{array}$ & $\begin{array}{l}\text { Australia, Canada, France, } \\
\text { Japan, Netherlands, New } \\
\text { Zealand, United States }\end{array}$ \\
\hline $\begin{array}{l}\text { Echocardiographic core } \\
\text { laboratory }\end{array}$ & Yes & Yes & Yes & Yes & Yes \\
\hline $\begin{array}{l}\text { Adjudication of deaths, } \\
\text { safety-related adverse } \\
\text { events }\end{array}$ & Independent CEC & Independent CEC & Independent CEC & Independent CEC & Independent CEC \\
\hline Patient selection & $\begin{array}{l}\text { Moderate or severe AS or } \\
\text { AR with clinical indication } \\
\text { for AVR (native or } \\
\text { prosthetic valve) }\end{array}$ & $\begin{array}{l}\text { - Severe AS or AR with } \\
\text { clinical indication for AVR } \\
\text { (native or prosthetic valve) } \\
\text { - Need for a } 17-\mathrm{mm} \\
\text { bioprosthetic valve }\end{array}$ & $\begin{array}{l}\text { - Severe AS } \\
\text { - NYHA class II or greater } \\
\text { - Increased risk of surgery } \\
\text { (ie, risk of death within } \\
30 \mathrm{~d} \geq 15 \% \text { and the risk of } \\
\text { death or irreversible } \\
\text { complications within } 30 \mathrm{~d} \\
\text { after surgery }<50 \% \text { ) }\end{array}$ & $\begin{array}{l}\text { - Symptomatic, severe AS } \\
\text { - Intermediate surgical risk } \\
\text { (ie, estimated risk of } 30- \\
\text { d surgical death of } 3 \% \text { - } \\
15 \% \text { using STS-PROM } \\
\text { criteria) }\end{array}$ & $\begin{array}{l}\text { - Severe AS with suitable } \\
\text { anatomy for TAVR or } \\
\text { surgery } \\
\text { - Predicted risk of death } \\
\text { within } 30 \mathrm{~d} \text { after surgery of } \\
\text { no more than } 3 \%\end{array}$ \\
\hline Key exclusion criteria & $\begin{array}{l}\text { - Pre-existing device in } \\
\text { another position } \\
\text { - Need for replacement or } \\
\text { repair of another valve } \\
\text { - Active endocarditis or other } \\
\text { infection } \\
\text { - Anatomic abnormality } \\
\text { - Life expectancy }<2 \text { y }\end{array}$ & $\begin{array}{l}\text { - Pre-existing device in } \\
\text { another position } \\
\text { - Need for replacement of } \\
\text { another valve } \\
\text { - Active endocarditis or other } \\
\text { infection } \\
\text { - Anatomic abnormality } \\
\text { - Life expectancy }<2 \text { y }\end{array}$ & $\begin{array}{l}\text { - } \text { AMI } \leq 30 \mathrm{~d} \text { before index } \\
\text { procedure } \\
\text { - Percutaneous/peripheral } \\
\text { BMS within } 30 \mathrm{~d} \text { or DES } \\
\text { within } 6 \text { mo of index } \\
\text { procedure } \\
\text { - Blood dyscrasias } \\
\text { - CAD requiring } \\
\text { revascularization } \\
\text { - Cardiogenic shock } \\
\text { - Severe LV dysfunction with } \\
\text { LVEF }<20 \% \\
\text { - CVA or TIA within } 6 \text { mo of } \\
\text { index procedure }\end{array}$ & $\begin{array}{l}\text { - Refusal of SAVR as a } \\
\text { treatment option } \\
\text { - Any contraindication for } \\
\text { placement of a } \\
\text { bioprosthetic valve (eg, } \\
\text { need for mechanical valve) } \\
\text { - Known hypersensitivity or } \\
\text { contraindication to all } \\
\text { anticoagulation/antiplatelet } \\
\text { regimens (or inability to be } \\
\text { anticoagulated for the index } \\
\text { procedure), nitinol, or } \\
\text { sensitivity to contrast } \\
\text { medium that cannot be } \\
\text { adequately pre-medicated } \\
\text { - Blood dyscrasias }\end{array}$ & $\begin{array}{l}\text { - Any contraindication to } \\
\text { placement of a } \\
\text { bioprosthetic valve (eg, } \\
\text { need for a mechanical } \\
\text { valve) } \\
\text { - Known hypersensitivity or } \\
\text { contraindication to any of } \\
\text { the following that cannot be } \\
\text { adequately premedicated: } \\
\text { (1) aspirin or heparin (HIT/ } \\
\text { HITTS) and bivalirudin; (2) } \\
\text { ticlopidine and clopidogrel; } \\
\text { (3) nitinol (titanium or } \\
\text { nickel); or (4) contrast } \\
\text { media } \\
\text { - Blood dyscrasias }\end{array}$ \\
\hline
\end{tabular}

\section{ADULT}


స్ TABLE E1. Continued

\begin{tabular}{|c|c|c|c|c|c|}
\hline & PERIGON Pivotal & PERIGON Japan & CoreValve High Risk & SURTAVI & Evolut Low Risk \\
\hline & & & & $\begin{array}{l}\text { - Ongoing sepsis, including } \\
\text { active endocarditis }\end{array}$ & $\begin{array}{l}\text { Ongoing sepsis, including } \\
\text { active endocarditis }\end{array}$ \\
\hline $\begin{array}{l}\text { Concomitant procedures } \\
\text { allowed in patients who } \\
\text { received a surgical AVR? }\end{array}$ & $\begin{array}{l}\text { - Yes, limited procedures } \\
\text { allowed }\end{array}$ & $\begin{array}{l}\text { - Yes, limited procedures } \\
\text { allowed }\end{array}$ & - No & $\begin{array}{l}\text { - Yes, limited procedures } \\
\text { allowed }\end{array}$ & $\begin{array}{l}\text { - Yes, limited procedures } \\
\text { allowed }\end{array}$ \\
\hline Primary end point(s) & $\begin{array}{l}\text { Safety: time-related } \\
\text { incidence of death and } \\
\text { valve-related adverse } \\
\text { events (thromboembolism, } \\
\text { thrombosis, hemorrhage } \\
\text { [all and major], } \\
\text { paravalvular leak [all and } \\
\text { major], endocarditis, } \\
\text { hemolysis, structural valve } \\
\text { deterioration, nonstructural } \\
\text { valve dysfunction, } \\
\text { reintervention, and explant) }\end{array}$ & $\begin{array}{l}\text { - Composite change in } \\
\text { NYHA class at } 1 \text { y } \\
\text { compared to baseline and } \\
\text { EOAi at } 1 \text { y post-implant } \\
\text { compared with } \\
\text { performance goal of } 60 \%\end{array}$ & - Rate of any death at 1 y & $\begin{array}{l}\text { Composite of death from } \\
\text { any cause or disabling } \\
\text { stroke at } 24 \text { mo }\end{array}$ & $\begin{array}{l}\text { All-cause mortality or } \\
\text { disabling stroke at } 2 \text { y }\end{array}$ \\
\hline $\begin{array}{l}\text { Planned maximum follow-up, } \\
\text { including TTE }\end{array}$ & $\begin{array}{l}\text { - } 5 \text { y for entire cohort, } 12 \text { y in } \\
\text { a LTFU cohort }\end{array}$ & - $5 \mathrm{y}$ & - $5 \mathrm{y}$ & - $5 \mathrm{y}, 10 \mathrm{y}$ in a LTFU cohort & - $10 \mathrm{y}$ \\
\hline $\begin{array}{l}C \text {, Clinical events committee; } \\
\text { scatheter aortic valve replacem } \\
\text { dent; } T I A \text {, transient ischemic a } \\
\text { aphy; EOAi, indexed effective }\end{array}$ & $\begin{array}{l}\text { ic stenosis; } A R \text {, aortic regurgitati } \\
I I \text {, acute myocardial infarction; } B A \\
A V R, \text { surgical aortic valve replace } \\
\text { area; } L T F U, \text { long-term follow-up. }\end{array}$ & $\begin{array}{l}A V R, \text { aortic valve replacement } \\
\text { bare metal stent; } D E S \text {, drug-elu } \\
\text { nt; } H I T / H I T T S \text {, heparin-induce } \\
\text { he numbers indicate only the } S\end{array}$ & $\begin{array}{l}\text { New York Heart Association } \\
\text { t; } C A D \text {, coronary artery diseas } \\
\text { bocytopenia and heparin-indu } \\
\text { tients included in the current }\end{array}$ & $\begin{array}{l}R O M, \text { Society of Thoracic Surg } \\
\text { ft ventricle; } L V E F \text {, left ventriculi } \\
\text { mbocytopenia with thrombosis } \\
\end{array}$ & $\begin{array}{l}\text { Predicted Risk of Mortality; TAVR } \\
\text { ction fraction; } C V A \text {, cerebrovascular } \\
\text { rome; } T T E \text {, transthoracic echocardi }\end{array}$ \\
\hline
\end{tabular}


TABLE E2. Distribution and sizing of valves implanted in the pooled surgical aortic valve replacement studies

\begin{tabular}{|c|c|c|c|c|c|c|}
\hline \multirow{2}{*}{$\begin{array}{c}\text { Implanted } \\
\text { surgical valve } \\
\text { (manufacturer) } \\
\text { and labeled size }\end{array}$} & \multirow[b]{2}{*}{$\begin{array}{c}\text { Overall cohort, } \\
\mathbf{N}=\mathbf{2 1 7 1} \\
\end{array}$} & \multicolumn{5}{|c|}{ Valve distribution across studies in the pooled analysis, $n(\%)$} \\
\hline & & $\begin{array}{l}\text { PERIGON Pivotal, } \\
\quad \mathbf{N}=1019\end{array}$ & $\begin{array}{l}\text { PERIGON Japan, } \\
\qquad \mathbf{N}=\mathbf{1 1}\end{array}$ & $\begin{array}{c}\text { CoreValve High } \\
\text { Risk, } N=214\end{array}$ & $\begin{array}{c}\text { SURTAVI, } \\
\mathbf{N}=\mathbf{5 7 4}\end{array}$ & $\begin{array}{c}\text { Evolut Low Risk, } \\
\mathbf{N}=\mathbf{3 5 3}\end{array}$ \\
\hline \multicolumn{7}{|l|}{ Mosaic (Medtronic) } \\
\hline $17 \mathrm{~mm}$ & $0(0.0 \%)$ & $0(0.0 \%)$ & $0(0.0 \%)$ & $0(0.0 \%)$ & $0(0.0 \%)$ & $0(0.0 \%)$ \\
\hline $19 \mathrm{~mm}$ & $4(0.2 \%)$ & $0(0.0 \%)$ & $0(0.0 \%)$ & $4(1.9 \%)$ & $0(0.0 \%)$ & $0(0.0 \%)$ \\
\hline $21 \mathrm{~mm}$ & $29(1.3 \%)$ & $0(0.0 \%)$ & $0(0.0 \%)$ & $6(2.8 \%)$ & $23(4.0 \%)$ & $0(0.0 \%)$ \\
\hline $23 \mathrm{~mm}$ & $65(3.0 \%)$ & $0(0.0 \%)$ & $0(0.0 \%)$ & $17(7.9 \%)$ & $36(6.3 \%)$ & $12(3.4 \%)$ \\
\hline $25 \mathrm{~mm}$ & $69(3.2 \%)$ & $0(0.0 \%)$ & $0(0.0 \%)$ & $18(8.4 \%)$ & $39(6.8 \%)$ & $12(3.4 \%)$ \\
\hline $27 \mathrm{~mm}$ & $13(0.6 \%)$ & $0(0.0 \%)$ & $0(0.0 \%)$ & $4(1.9 \%)$ & $4(0.7 \%)$ & $5(1.4 \%)$ \\
\hline $29 \mathrm{~mm}$ & $1(0.0 \%)$ & $0(0.0 \%)$ & $0(0.0 \%)$ & $1(0.5 \%)$ & $0(0.0 \%)$ & $0(0.0 \%)$ \\
\hline \multicolumn{7}{|l|}{ Hancock II (Medtronic) } \\
\hline $17 \mathrm{~mm}$ & $0(0.0 \%)$ & $0(0.0 \%)$ & $0(0.0 \%)$ & $0(0.0 \%)$ & $0(0.0 \%)$ & $0(0.0 \%)$ \\
\hline $19 \mathrm{~mm}$ & $0(0.0 \%)$ & $0(0.0 \%)$ & $0(0.0 \%)$ & $0(0.0 \%)$ & $0(0.0 \%)$ & $0(0.0 \%)$ \\
\hline $21 \mathrm{~mm}$ & $6(0.3 \%)$ & $0(0.0 \%)$ & $0(0.0 \%)$ & $2(0.9 \%)$ & $4(0.7 \%)$ & $0(0.0 \%)$ \\
\hline $23 \mathrm{~mm}$ & $15(0.7 \%)$ & $0(0.0 \%)$ & $0(0.0 \%)$ & $6(2.8 \%)$ & $5(0.9 \%)$ & $4(1.1 \%)$ \\
\hline $25 \mathrm{~mm}$ & $16(0.7 \%)$ & $0(0.0 \%)$ & $0(0.0 \%)$ & $4(1.9 \%)$ & $5(0.9 \%)$ & $7(2.0 \%)$ \\
\hline $27 \mathrm{~mm}$ & $6(0.3 \%)$ & $0(0.0 \%)$ & $0(0.0 \%)$ & $0(0.0 \%)$ & $3(0.5 \%)$ & $3(0.8 \%)$ \\
\hline $29 \mathrm{~mm}$ & $2(0.1 \%)$ & $0(0.0 \%)$ & $0(0.0 \%)$ & $0(0.0 \%)$ & $1(0.2 \%)$ & $1(0.3 \%)$ \\
\hline \multicolumn{7}{|c|}{ Biocor/Epic (SJM/Abbott) } \\
\hline $17 \mathrm{~mm}$ & $0(0.0 \%)$ & $0(0.0 \%)$ & $0(0.0 \%)$ & $0(0.0 \%)$ & $0(0.0 \%)$ & $0(0.0 \%)$ \\
\hline $19 \mathrm{~mm}$ & $1(0.0 \%)$ & $0(0.0 \%)$ & $0(0.0 \%)$ & $1(0.5 \%)$ & $0(0.0 \%)$ & $0(0.0 \%)$ \\
\hline $21 \mathrm{~mm}$ & $11(0.5 \%)$ & $0(0.0 \%)$ & $0(0.0 \%)$ & $5(2.3 \%)$ & $5(0.9 \%)$ & $1(0.3 \%)$ \\
\hline $23 \mathrm{~mm}$ & $9(0.4 \%)$ & $0(0.0 \%)$ & $0(0.0 \%)$ & $4(1.9 \%)$ & $2(0.3 \%)$ & $3(0.8 \%)$ \\
\hline $25 \mathrm{~mm}$ & $5(0.2 \%)$ & $0(0.0 \%)$ & $0(0.0 \%)$ & $0(0.0 \%)$ & $3(0.5 \%)$ & $2(0.6 \%)$ \\
\hline $27 \mathrm{~mm}$ & $0(0.0 \%)$ & $0(0.0 \%)$ & $0(0.0 \%)$ & $0(0.0 \%)$ & $0(0.0 \%)$ & $0(0.0 \%)$ \\
\hline $29 \mathrm{~mm}$ & $0(0.0 \%)$ & $0(0.0 \%)$ & $0(0.0 \%)$ & $0(0.0 \%)$ & $0(0.0 \%)$ & $0(0.0 \%)$ \\
\hline \multicolumn{7}{|l|}{ Avalus (Medtronic) } \\
\hline $17 \mathrm{~mm}$ & $12(0.6 \%)$ & $1(0.1 \%)$ & $11(100.0 \%)$ & $0(0.0 \%)$ & $0(0.0 \%)$ & $0(0.0 \%)$ \\
\hline $19 \mathrm{~mm}$ & $36(1.7 \%)$ & $36(3.5 \%)$ & $0(0.0 \%)$ & $0(0.0 \%)$ & $0(0.0 \%)$ & $0(0.0 \%)$ \\
\hline $21 \mathrm{~mm}$ & $196(9.0 \%)$ & $196(19.2 \%)$ & $0(0.0 \%)$ & $0(0.0 \%)$ & $0(0.0 \%)$ & $0(0.0 \%)$ \\
\hline $23 \mathrm{~mm}$ & $363(16.7 \%)$ & $363(35.6 \%)$ & $0(0.0 \%)$ & $0(0.0 \%)$ & $0(0.0 \%)$ & $0(0.0 \%)$ \\
\hline $25 \mathrm{~mm}$ & $323(14.9 \%)$ & $322(31.6 \%)$ & $0(0.0 \%)$ & $0(0.0 \%)$ & $0(0.0 \%)$ & $1(0.3 \%)$ \\
\hline $27 \mathrm{~mm}$ & $92(4.2 \%)$ & $92(9.0 \%)$ & $0(0.0 \%)$ & $0(0.0 \%)$ & $0(0.0 \%)$ & $0(0.0 \%)$ \\
\hline $29 \mathrm{~mm}$ & $9(0.4 \%)$ & $9(0.9 \%)$ & $0(0.0 \%)$ & $0(0.0 \%)$ & $0(0.0 \%)$ & $0(0.0 \%)$ \\
\hline \multicolumn{7}{|c|}{ PERIMOUNT (Edwards) } \\
\hline $17 \mathrm{~mm}$ & $0(0.0 \%)$ & $0(0.0 \%)$ & $0(0.0 \%)$ & $0(0.0 \%)$ & $0(0.0 \%)$ & $0(0.0 \%)$ \\
\hline $19 \mathrm{~mm}$ & $18(0.8 \%)$ & $0(0.0 \%)$ & $0(0.0 \%)$ & $6(2.8 \%)$ & $9(1.6 \%)$ & $3(0.8 \%)$ \\
\hline $21 \mathrm{~mm}$ & $140(6.4 \%)$ & $0(0.0 \%)$ & $0(0.0 \%)$ & $30(14.0 \%)$ & $70(12.2 \%)$ & $40(11.3 \%)$ \\
\hline $23 \mathrm{~mm}$ & $215(9.9 \%)$ & $0(0.0 \%)$ & $0(0.0 \%)$ & $27(12.6 \%)$ & $106(18.5 \%)$ & $82(23.2 \%)$ \\
\hline $25 \mathrm{~mm}$ & $135(6.2 \%)$ & $0(0.0 \%)$ & $0(0.0 \%)$ & $11(5.1 \%)$ & $65(11.3 \%)$ & $59(16.7 \%)$ \\
\hline $27 \mathrm{~mm}$ & $31(1.4 \%)$ & $0(0.0 \%)$ & $0(0.0 \%)$ & $1(0.5 \%)$ & $16(2.8 \%)$ & $14(4.0 \%)$ \\
\hline $29 \mathrm{~mm}$ & $3(0.1 \%)$ & $0(0.0 \%)$ & $0(0.0 \%)$ & $1(0.5 \%)$ & $2(0.3 \%)$ & $0(0.0 \%)$ \\
\hline \multicolumn{7}{|l|}{ Mitroflow (Sorin) } \\
\hline $17 \mathrm{~mm}$ & $0(0.0 \%)$ & $0(0.0 \%)$ & $0(0.0 \%)$ & $0(0.0 \%)$ & $0(0.0 \%)$ & $0(0.0 \%)$ \\
\hline $19 \mathrm{~mm}$ & $2(0.1 \%)$ & $0(0.0 \%)$ & $0(0.0 \%)$ & $2(0.9 \%)$ & $0(0.0 \%)$ & $0(0.0 \%)$ \\
\hline $21 \mathrm{~mm}$ & $17(0.8 \%)$ & $0(0.0 \%)$ & $0(0.0 \%)$ & $8(3.7 \%)$ & $9(1.6 \%)$ & $0(0.0 \%)$ \\
\hline $23 \mathrm{~mm}$ & $8(0.4 \%)$ & $0(0.0 \%)$ & $0(0.0 \%)$ & $4(1.9 \%)$ & $1(0.2 \%)$ & $3(0.8 \%)$ \\
\hline $25 \mathrm{~mm}$ & $4(0.2 \%)$ & $0(0.0 \%)$ & $0(0.0 \%)$ & $4(1.9 \%)$ & $0(0.0 \%)$ & $0(0.0 \%)$ \\
\hline $27 \mathrm{~mm}$ & $0(0.0 \%)$ & $0(0.0 \%)$ & $0(0.0 \%)$ & $0(0.0 \%)$ & $0(0.0 \%)$ & $0(0.0 \%)$ \\
\hline $29 \mathrm{~mm}$ & $0(0.0 \%)$ & $0(0.0 \%)$ & $0(0.0 \%)$ & $0(0.0 \%)$ & $0(0.0 \%)$ & $0(0.0 \%)$ \\
\hline
\end{tabular}


TABLE E2. Continued

\begin{tabular}{|c|c|c|c|c|c|c|}
\hline \multirow{2}{*}{$\begin{array}{c}\text { Implanted } \\
\text { surgical valve } \\
\text { (manufacturer) } \\
\text { and labeled size }\end{array}$} & \multirow[b]{2}{*}{$\begin{array}{l}\text { Overall cohort, } \\
\quad \mathrm{N}=\mathbf{2 1 7 1}\end{array}$} & \multicolumn{5}{|c|}{ Valve distribution across studies in the pooled analysis, $\mathbf{n}(\%)$} \\
\hline & & $\begin{array}{l}\text { PERIGON Pivotal, } \\
\qquad \mathbf{N}=1019\end{array}$ & $\begin{array}{l}\text { PERIGON Japan, } \\
\qquad \mathbf{N}=\mathbf{1 1}\end{array}$ & $\begin{array}{c}\text { CoreValve High } \\
\text { Risk, } N=214\end{array}$ & $\begin{array}{l}\text { SURTAVI, } \\
\text { N = 574 }\end{array}$ & $\begin{array}{c}\text { Evolut Low Risk, } \\
\quad \mathbf{N}=\mathbf{3 5 3}\end{array}$ \\
\hline \multicolumn{7}{|l|}{ Trifecta (SJM/Abbott) } \\
\hline $17 \mathrm{~mm}$ & $0(0.0 \%)$ & $0(0.0 \%)$ & $0(0.0 \%)$ & $0(0.0 \%)$ & $0(0.0 \%)$ & $0(0.0 \%)$ \\
\hline $19 \mathrm{~mm}$ & $33(1.5 \%)$ & $0(0.0 \%)$ & $0(0.0 \%)$ & $5(2.3 \%)$ & $19(3.3 \%)$ & $9(2.5 \%)$ \\
\hline $21 \mathrm{~mm}$ & $103(4.7 \%)$ & $0(0.0 \%)$ & $0(0.0 \%)$ & $15(7.0 \%)$ & $57(9.9 \%)$ & $31(8.8 \%)$ \\
\hline $23 \mathrm{~mm}$ & $105(4.8 \%)$ & $0(0.0 \%)$ & $0(0.0 \%)$ & $15(7.0 \%)$ & $59(10.3 \%)$ & $31(8.8 \%)$ \\
\hline $25 \mathrm{~mm}$ & $49(2.3 \%)$ & $0(0.0 \%)$ & $0(0.0 \%)$ & $8(3.7 \%)$ & $21(3.7 \%)$ & $20(5.7 \%)$ \\
\hline $27 \mathrm{~mm}$ & $15(0.7 \%)$ & $0(0.0 \%)$ & $0(0.0 \%)$ & $5(2.3 \%)$ & $6(1.0 \%)$ & $4(1.1 \%)$ \\
\hline $29 \mathrm{~mm}$ & $2(0.1 \%)$ & $0(0.0 \%)$ & $0(0.0 \%)$ & $0(0.0 \%)$ & $1(0.2 \%)$ & $1(0.3 \%)$ \\
\hline \multicolumn{7}{|l|}{ Other surgical valve } \\
\hline $17 \mathrm{~mm}$ & $1(0.0 \%)$ & $0(0.0 \%)$ & $0(0.0 \%)$ & $0(0.0 \%)$ & $1(0.2 \%)$ & $0(0.0 \%)$ \\
\hline $19 \mathrm{~mm}$ & $0(0.0 \%)$ & $0(0.0 \%)$ & $0(0.0 \%)$ & $0(0.0 \%)$ & $0(0.0 \%)$ & $0(0.0 \%)$ \\
\hline $21 \mathrm{~mm}$ & $1(0.0 \%)$ & $0(0.0 \%)$ & $0(0.0 \%)$ & $0(0.0 \%)$ & $0(0.0 \%)$ & $1(0.3 \%)$ \\
\hline $23 \mathrm{~mm}$ & $3(0.1 \%)$ & $0(0.0 \%)$ & $0(0.0 \%)$ & $0(0.0 \%)$ & $1(0.2 \%)$ & $2(0.6 \%)$ \\
\hline $25 \mathrm{~mm}$ & $3(0.1 \%)$ & $0(0.0 \%)$ & $0(0.0 \%)$ & $0(0.0 \%)$ & $1(0.2 \%)$ & $2(0.6 \%)$ \\
\hline $27 \mathrm{~mm}$ & $0(0.0 \%)$ & $0(0.0 \%)$ & $0(0.0 \%)$ & $0(0.0 \%)$ & $0(0.0 \%)$ & $0(0.0 \%)$ \\
\hline $29 \mathrm{~mm}$ & $0(0.0 \%)$ & $0(0.0 \%)$ & $0(0.0 \%)$ & $0(0.0 \%)$ & $0(0.0 \%)$ & $0(0.0 \%)$ \\
\hline
\end{tabular}

SJM, St Jude Medical.

TABLE E3. Diagnostic measures of different PPM criteria to reflect elevated mean aortic gradients ( $\geq 20 \mathrm{~mm} \mathrm{Hg}$ )

\begin{tabular}{lccccc}
\hline & Sensitivity $(\%)$ & Specificity $(\%)$ & Positive predictive value $(\%)$ & Negative predictive value $(\%)$ & Accuracy $(\%)$ \\
\hline ASE criteria & 92 & 45 & 13 & 98 & 49 \\
VARC-2 criteria & 83 & 54 & 14 & 97 & 57 \\
EACVI criteria & 83 & 54 & 14 & 97 & 57 \\
\hline
\end{tabular}

PPM, prosthesis-patient mismatch; ASE, American Society of Echocardiography; VARC-2, Valve Academic Research Consortium-2; EACVI, European Association of Cardiovascular Imaging. 
TABLE E4. Interaction of patient characteristics on the relation between EOAi and mean gradient $*$

\begin{tabular}{|c|c|c|}
\hline & \multicolumn{2}{|c|}{ 1-y follow-up } \\
\hline & $\overline{\text { Effect estimate }(95 \% \mathrm{CI})}$ & $P$ value \\
\hline \multicolumn{3}{|l|}{ Body mass index } \\
\hline EOAi & $-0.794(-0.865,-0.722)$ & $<.0001$ \\
\hline Body mass index $\geq 30 \mathrm{~kg} / \mathrm{m}^{2}$ & $0.106(0.005,0.207)$ & .0400 \\
\hline EOAi/body mass index interaction & $-0.075(-0.192,0.041)$ & .2042 \\
\hline \multicolumn{3}{|l|}{ Age } \\
\hline EOAi & $-0.894(-1.020,-0.769)$ & $<.0001$ \\
\hline Age $\geq 70 y$ & $-0.085(-0.202,0.032)$ & .1552 \\
\hline EOAi/age interaction & $0.086(-0.055,0.227)$ & .2301 \\
\hline \multicolumn{3}{|l|}{ Left ventricular ejection fraction } \\
\hline EOAi & $-0.850(-0.910,-0.791)$ & $<.0001$ \\
\hline Left ventricular ejection fraction $\leq 45 \%$ & $-0.136(-0.347,0.075)$ & .2069 \\
\hline EOAi/left ventricular ejection fraction interaction & $-0.021(-0.277,0.236)$ & .8752 \\
\hline \multicolumn{3}{|l|}{ Sex } \\
\hline EOAi & $-0.890(-0.987,-0.792)$ & $<.0001$ \\
\hline Male sex & $-0.121(-0.225,-0.016)$ & .0239 \\
\hline EOAi/gender interaction & $0.093(-0.027,0.212)$ & .1279 \\
\hline \multicolumn{3}{|l|}{ Stroke volume index } \\
\hline EOAi & $-1.008(-1.067,-0.948)$ & $<.0001$ \\
\hline Stroke volume index $<35 \mathrm{~mL} / \mathrm{m}^{2}$ & $0.115(0.007,0.223)$ & .0372 \\
\hline EOAi/stroke volume index interaction & $-0.666(-0.809,-0.523)$ & $<.0001$ \\
\hline
\end{tabular}

